\title{
Nitrous oxide added at the end of isoflurane anesthesia hastens early recovery without increasing the risk for postoperative nausea and vomiting: a randomized clinical trial L'ajout de protoxyde d'azote à la fin d'une anesthésie à l'isoflurane accélère la récupération précoce sans augmenter le risque de nausées et vomissements postopératoires : une étude clinique randomisée
}

\author{
Boris Mraovic, MD • Tatjana Simurina, MD, PhD • Tong J. Gan, MD \\ Received: 9 February 2017/ Accepted: 8 November 2017/Published online: 17 November 2017 \\ (C) Canadian Anesthesiologists' Society 2017
}

\begin{abstract}
Background Nitrous oxide $\left(\mathrm{N}_{2} \mathrm{O}\right)$ has been reported to increase the risk of postoperative nausea and vomiting $(P O N V)$ in a dose-dependent manner. We investigated the effect of adding $\mathrm{N}_{2} \mathrm{O}$ at the end of isoflurane inhalational anesthesia on the recovery and incidence of PONV. Our hypothesis was that $\mathrm{N}_{2} \mathrm{O}$ would reduce the time to early recovery without increasing the incidence of PONV.
\end{abstract}

Preliminary data were presented at CAS meeting, Toronto, June 2011 and awarded Best Paper in Ambulatory Anesthesia.

This article is accompanied by an editorial. Please see Can J Anesth 2018; 65: this issue.

B. Mraovic, MD ( $\square)$

Department of Anesthesiology \& Perioperative Medicine,

School of Medicine, University of Missouri - Columbia, One

Hospital Drive, Rm 3W-40F DC005.00, Columbia, MO 65212,

USA

e-mail: mraovicb@health.missouri.edu

T. Simurina, MD, PhD

Faculty of Medicine, University of Osijek, Osijek, Croatia

e-mail: tsimurina@unizd.hr

T. Simurina, MD, PhD

Department of Health Study, University of Zadar, Zadar, Croatia

T. Simurina, $\mathrm{MD}, \mathrm{PhD}$

Department of Anesthesiology and ICU, General Hospital,

Zadar, Croatia

T. J. Gan, MD

Department of Anesthesiology, Stony Brook University, Stony

Brook, NY, USA

e-mail: tong.gan@stonybrookmedicine.edu
Methods After obtaining ethics committee approval and written informed consent, 100 women at American Society of Anesthesiologists physical status I-III and scheduled for laparoscopic-assisted vaginal hysterectomy were randomized into two groups $(G)$ according to the carrier gas: $\mathrm{GO}_{2}$ (air in $30 \%$ oxygen) and $\mathrm{GN}_{2} \mathrm{O}$ (the same mixture until the last 30 min of surgery, when $70 \% \mathrm{~N}_{2} \mathrm{O}$ in $30 \%$ oxygen was used). No PONV prophylaxis was given. Anesthesia was induced with thiopental $5 \mathrm{mg} \cdot \mathrm{kg}^{-1}$, vecuronium $0.1 \mathrm{mg} \cdot \mathrm{kg}^{-1}$, and fentanyl $1-2 \mu \mathrm{g} \cdot \mathrm{kg}^{-1}$ iv and maintained with isoflurane. Indicators of early recovery (time to extubation, eye opening, following commands, orientation) were assessed by an anesthesiologist unaware of the group assignment. The incidence and severity of PONV was measured at two and $24 \mathrm{hr}$ postoperatively.

Results Altogether, 82 participants completed the study (42 in $\mathrm{GO}_{2}, 40$ in $\mathrm{GN}_{2} \mathrm{O}$ ) and were analyzed. The mean ( $S D$ ) time of $\mathrm{N}_{2} \mathrm{O}$ administration in $\mathrm{GN}_{2} \mathrm{O}$ patients was 27.1 (10.1) min. The mean (SD) time to extubation was faster in $\mathrm{GN}_{2} \mathrm{O}$ patients [5.4 (2.9) min] than in $\mathrm{GO}_{2}$ patients [7.5 (3.7) $\mathrm{min}$ ] (mean difference, $2.0 \mathrm{~min}$; $95 \%$ confidence interval [CI], 0.6 to 3.4, $P=0.009$ ). The ability to open eyes, follow commands, and being oriented were all faster in $\mathrm{GN}_{2} \mathrm{O}$ patients than in $\mathrm{GO}_{2}$ patients (differences of 3.9 $\min , 95 \% \mathrm{CI}, 1.6$ to $6.1, P=0.001 ; 3.4 \mathrm{~min}, 95 \% \mathrm{CI}, 1.0$ to 5.7, $P=0.006$; $3.8 \mathrm{~min}, 95 \% \mathrm{CI}, 0.9$ to $6.7, P=0.010$, respectively). The incidence of $P O N V$ was not different between the groups, but the rescue antiemetic was required less often in the $\mathrm{GN}_{2} \mathrm{O}$ patients (mean difference in metoclopramide dose between the $\mathrm{GN}_{2} \mathrm{O}$ and $\mathrm{GO}_{2}$ groups, $5.1 \mathrm{mg}$; 95\% CI, 0.8 to 9.4, $P=0.019$ ). 
Conclusions Adding $\mathrm{N}_{2} \mathrm{O}$ during the last $30 \mathrm{~min}$ of an isoflurane-based inhalational anesthetic reduced the time to extubation, eye opening, and orientation.

\section{Résumé}

Contexte Selon des études, le protoxyde d'azote $\left(\mathrm{N}_{2} \mathrm{O}\right)$ augmenterait le risque de nausées et vomissements postopératoires (NVPO) de façon dose-dépendante. Nous avons évalué l'effet d'un ajout de $\mathrm{N}_{2} \mathrm{O}$ à la fin d'une anesthésie par inhalation d'isoflurane sur la récupération et l'incidence de NVPO. Notre hypothèse était que le $\mathrm{N}_{2} \mathrm{O}$ réduirait le temps de récupération précoce sans augmenter l'incidence de NVPO.

Méthode Après avoir obtenu l'approbation du comité d'éthique et le consentement éclairé écrit, 100 femmes de statut physique I-III selon l'American Society of Anesthesiologists devant subir une hystérectomie vaginale assistée par laparoscopie ont été réparties en deux groupes (G) selon le gaz de transport: $\mathrm{GO}_{2}$ (air avec $30 \%$ oxygène) et $\mathrm{GN}_{2} \mathrm{O}$ (le même mélange jusqu'aux 30 dernières min de chirurgie, puis $70 \% \mathrm{~N}_{2} \mathrm{O}$ avec $30 \%$ oxygène). Aucune prophylaxie anti-NVPO n'a été administrée. L'anesthésie a été induite à l'aide de 5 $\mathrm{mg} \cdot \mathrm{kg}^{-1}$ de thiopental, $0,1 \mathrm{mg} \cdot \mathrm{kg}^{-1}$ de vécuronium, et 1-2 $\mu \mathrm{g} \cdot \mathrm{kg}^{-1}$ de fentanyl iv, et maintenue à l'aide d'isoflurane. Les indicateurs de récupération précoce (soit le temps jusqu'à l'extubation, jusqu'à l'ouverture des yeux, à la réponse aux ordres, à l'orientation) ont été évalués par un anesthésiologiste ignorant l'attribution de groupe. L'incidence et la gravité des NVPO ont été mesurées à deux et 24 h postopératoires.

Résultats $\mathrm{Au}$ total, 82 participantes ont terminé l'étude (42 dans le groupe $\mathrm{GO}_{2}, 40$ dans le groupe $\mathrm{GN}_{2} \mathrm{O}$ ) et leurs résultats ont été analysés. La durée moyenne (ÉT) d'administration de $\mathrm{N}_{2} \mathrm{O}$ chez les patientes du groupe $\mathrm{GN}_{2} \mathrm{O}$ était de 27,1 (10,1) min. Le temps moyen (ÉT) jusqu'à l'extubation était plus court chez les patientes du groupe $\mathrm{GN}_{2} \mathrm{O}$ [5,4 (2,9) min] que chez celles du groupe $\mathrm{GO}_{2} \quad[7,5$ (3,7) min] (différence moyenne, 2,0 min; intervalle de confiance [IC] $95 \%, 0,6$ à 3,4, P = 0,009). La capacité à ouvrir les yeux, à obéir à des ordres et à s'orienter se sont rétablies plus rapidement dans le groupe $\mathrm{GN}_{2} \mathrm{O}$ que dans le groupe $\mathrm{GO}_{2}$ (différences de 3,9 min, IC $95 \%, 1,6$ à 6,1, $P=0,001 ; 3,4$ min, IC $95 \%, 1,0$ à 5,7, $P$ $=0,006 ; 3,8 \mathrm{~min}$, IC $95 \%, 0,9$ à 6,7, $P=0,010$, respectivement). L'incidence de NVPO n'était pas différente entre les groupes, mais l'antiémétique de sauvetage a été moins souvent requis dans le groupe $\mathrm{GN}_{2} \mathrm{O}$ (différence moyenne de dose de métoclopramide entre les groupes $\mathrm{GN}_{2} \mathrm{O}$ et $\mathrm{GO}_{2}, 5,1 \mathrm{mg}$; IC $95 \%, 0,8$ à 9,4, $P=0,019$ ).

Conclusion L'ajout de $\mathrm{N}_{2} \mathrm{O}$ au cours des 30 dernières minutes d'une anesthésie par inhalation d'isoflurane a réduit le délai jusqu'à l'extubation, l'ouverture des yeux et l'orientation.

The older volatile anesthetic (VA) isoflurane is less expensive per milliliter than the newer VAs, such as sevoflurane and desflurane. Isoflurane's higher blood/gas solubility, however, increases the context decrement time, resulting in longer recovery from anesthesia. A metaanalysis showed that patients followed commands, on average, $4.4 \mathrm{~min}$ earlier with desflurane than with isoflurane. ${ }^{1}$ In longer cases, when the total dose of VA is significantly higher and wake-up time is more prolonged, it may seem logical to use an older, less expensive VA with higher blood/gas solubility for anesthesia maintenance and then switch to a more costly VA with a faster wake-up profile towards the end of anesthesia. A study of volunteers undergoing general anesthesia, however, showed that switching from isoflurane to desflurane at the end of the anesthesia did not hasten recovery. ${ }^{2}$

Another option to reduce the overall consumption of VA is to add nitrous oxide $\left(\mathrm{N}_{2} \mathrm{O}\right)$ as a carrier gas. Nitrous oxide has been used for its minimum alveolar concentration (MAC) sparing effect and accelerates awakening after general anesthesia. ${ }^{3}$ Nevertheless, $\mathrm{N}_{2} \mathrm{O}$ has side effects, such as a risk of postoperative nausea and vomiting (PONV) in a dose-dependent manner and with prolonged duration. ${ }^{4,5}$ Some anesthesia providers choose to add $\mathrm{N}_{2} \mathrm{O}$ at the end of anesthesia to hasten awakening and extubation in the operating room (OR), but this practice has not been well investigated.

We therefore investigated the addition of $\mathrm{N}_{2} \mathrm{O}$ towards the end of isoflurane anesthetic regarding its influence on the time to awakening and the appearance of PONV. We hypothesized that the addition of $\mathrm{N}_{2} \mathrm{O} 30 \mathrm{~min}$ before the expected end of surgery would reduce the time to early recovery without increasing the incidence of PONV.

\section{Methods}

After obtaining approval of the Ethical Committee of General Hospital Zadar, Croatia (IRB approval 01-2661-2/ 06) and written informed consent from the patients, we enrolled 100 adult women at American Society of Anesthesiologists (ASA) physical status I-III in the study who were to undergo general anesthesia for elective laparoscopic-assisted vaginal hysterectomy.

We excluded subjects with potentially confounding factors that could increase the risk of PONV and/or prolong routine laparoscopic surgery. Exclusion criteria were pregnancy; recently having given birth or within less than two months after termination of pregnancy; 


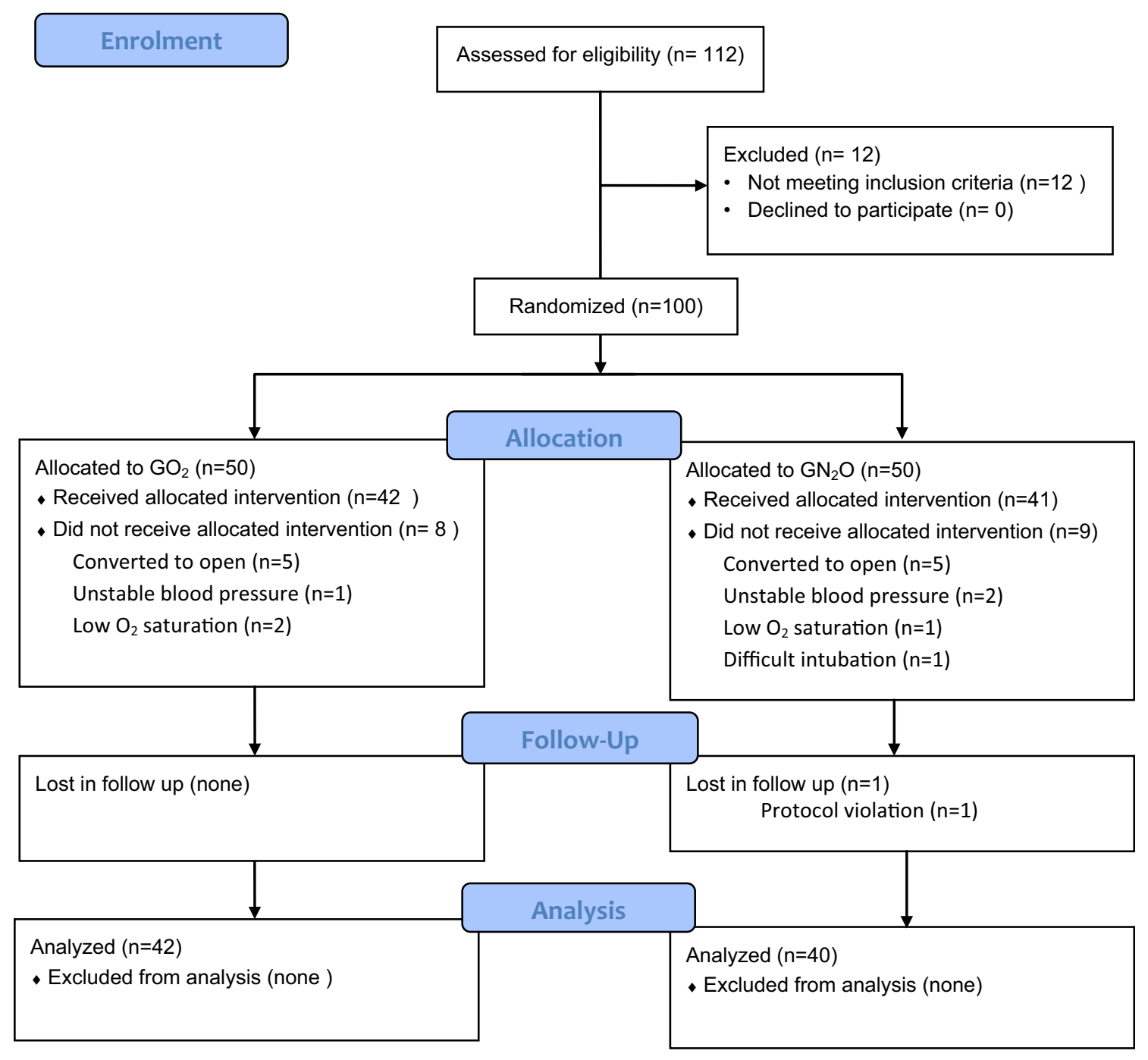

Figure CONSORT diagram for subject enrolment

breastfeeding; obesity (body mass index $>30 \mathrm{~kg} \cdot \mathrm{m}^{-2}$ ); known hypersensitivity to drugs used in the study protocol; use of antiemetics, psychotropic drugs, hormones, and/or steroids within $72 \mathrm{hr}$ before surgery; nausea and/or vomiting immediately prior to surgery; history of multiple laparotomies; diseases that impair gastric motility (diabetes mellitus, chronic cholecystitis, gastric and intestinal disease, neuromuscular disorders, neuropathies, liver dysfunction); vestibular disease; history of migraine headaches, central nervous system injury, renal impairment, alcoholism, and/or opioid addiction. Subjects were also excluded (post-randomization) if they developed conditions that could influence the incidence of PONV, postoperative pain or morbidity (e.g., significant intraoperative surgery complications), intraoperative drug allergy, severe intraoperative hypotension, perioperative hypoxia, excessive blood loss, difficult intubation, or if the surgery had been converted to an open approach.
Preoperatively, all subjects fasted at least six hours but were allowed to drink clear fluids up to two hours before the surgery and received midazolam $7.5 \mathrm{mg}$ po one hour before the surgery. No prophylactic antiemetics were given as it was the hospital's standard procedure at the time of the study. Standard intraoperative monitoring included electrocardiography, noninvasive blood pressure, pulse oximetry, and capnography. Anesthesia was induced with thiopental $5 \mathrm{mg} \cdot \mathrm{kg}^{-1}$, fentanyl $1-2 \mu \mathrm{g} \cdot \mathrm{kg}^{-1}$, and vecuronium $0.1 \mathrm{mg} \cdot \mathrm{kg}^{-1} i v$. All subjects received 500 $\mathrm{mL}$ of saline prior to surgery and crystalloids 10 $\mathrm{mL} \cdot \mathrm{kg}^{-1} \cdot \mathrm{hr}^{-1}$ during surgery. The lungs were manually ventilated via face mask with oxygen $6 \mathrm{~L} \cdot \mathrm{min}^{-1}$ for three minutes before the trachea was intubated.

Subjects were randomized into the two groups by computer-generated random numbers. Each allocation number was concealed in an opaque envelope before the start of the surgery and was revealed $30 \mathrm{~min}$ before the end 
Table 1 Demographics and intraoperative data

\begin{tabular}{llc}
\hline & $\begin{array}{l}\mathrm{GO}_{2}(\mathrm{air}) \\
(n=42)\end{array}$ & $\begin{array}{l}\mathrm{GN}_{2} \mathrm{O}\left(\mathrm{air} / \mathrm{N}_{2} \mathrm{O}\right) \\
(n=40)\end{array}$ \\
\hline Age (yr) & $51.4(8.3)$ & $48.6(6.7)$ \\
Body mass index $\left(\mathrm{kg} \cdot \mathrm{m}^{-2}\right)$ & $25.4(3.3)$ & $26.4(3.8)$ \\
ASA physical status & & \\
I & $16(38)$ & $23(57)$ \\
II & $24(57)$ & $17(33)$ \\
III & $2(5)$ & $0(0)$ \\
H/o PONV or motion sickness & $20(48)$ & $15(38)$ \\
Smoking & $16(38)$ & $14(35)$ \\
Apfel score & & \\
2 & $10(24)$ & $13(33)$ \\
3 & $18(43)$ & $20(50)$ \\
4 & $14(33)$ & $7(18)$ \\
Probability for PONV (Apfel score) & $0.61(0.15)$ & $0.57(0.14)$ \\
Surgery time (min) & $88.8(26.7)$ & $94.1(26.5)$ \\
Anesthesia time (min) & $106.1(26.1)$ & $112.3(27.2)$ \\
Nitrous oxide time (min) & 0 & $27.1(10.1)$ \\
Thiopental (mg) & $342.8(44.3)$ & $355.0(54.9)$ \\
Fentanyl ( $\mu \mathrm{g})$ & $235.1(45.8)$ & $238.7(38.7)$ \\
\hline
\end{tabular}

Data presented as mean (SD) and $n(\%)$

ASA = American Society of Anesthesiology; $\mathrm{GO}_{2}=$ oxygen Group; $\mathrm{GN}_{2} \mathrm{O}=$ nitrous oxide Group; $\mathrm{H} / \mathrm{o}=$ history of; $\mathrm{PONV}=$ postoperative nausea and vomiting

of the operation. The oxygen group $\left(\mathrm{GO}_{2}\right)$ received air in $30 \% \mathrm{O}_{2}$ throughout the procedure. The nitrous oxide group $\left(\mathrm{GN}_{2} \mathrm{O}\right)$ received the same carrier gas mixture until the last 30 min of surgery, when $70 \% \quad \mathrm{~N}_{2} \mathrm{O}$ in $30 \% \quad \mathrm{O}_{2}$ was administered. Anesthesia was maintained with isoflurane at $\sim 1$ MAC delivered in fresh gas flow at $3 \mathrm{~L} \cdot \mathrm{min}^{-1}$.

In $\mathrm{GO}_{2}$ patients, the end-tidal concentration of isoflurane was maintained at $\sim 1 \mathrm{MAC}$. Isoflurane was discontinued at the start of skin closure. In $\mathrm{GN}_{2} \mathrm{O}$ patients, $\mathrm{N}_{2} \mathrm{O}$ was started 30 min before skin closure, with the concentration adjusted to keep the total anesthetic concentration (isoflurane $+\mathrm{N}_{2} \mathrm{O}$ ) at $\sim 1$ MAC. Both isoflurane and $\mathrm{N}_{2} \mathrm{O}$ were discontinued at the start of skin closure. Supplemental bolus doses of fentanyl $\left(1 \mu \mathrm{g} \cdot \mathrm{kg}^{-1} i \mathrm{v}\right)$ were given to keep the heart rate and blood pressure within $20 \%$ of baseline values in both groups, and additional doses of vecuronium were administered to maintain one to two twitches on the train-of-four neuromuscular monitor.

The lungs were mechanically ventilated to maintain normocapnia (end-tidal $\mathrm{CO}_{2} 36-38 \mathrm{mmHg}$ ). A nasogastric tube was not placed. All laparoscopy-assisted operations were performed with $\mathrm{CO}_{2}$ insufflation to an intraabdominal pressure of $15 \mathrm{mmHg}$. At the end of the surgery, the fresh gas inflow rate was changed to $6 \mathrm{~L} \cdot \mathrm{min}^{-1}$ of $100 \% \mathrm{O}_{2}$, and the neuromuscular blockade was reversed (neostigmine 2.5 $\mathrm{mg}$ and atropine $1 \mathrm{mg} i v$ ) in all subjects.

Extubation criteria were standardized to meet the usual criteria for extubation in our hospital. Subjects were extubated when the spontaneous tidal volume was $>300$ $\mathrm{mL}$, respiratory rate was $>8$ breaths $\cdot \mathrm{min}^{-1}$, and end-tidal $\mathrm{CO}_{2}$ was $\leq 45 \mathrm{mmHg}$. The patients were monitored in the OR until they opened their eyes and followed commands. Early recovery (time to extubation, eye opening, following verbal commands, orientation to time and place) was recorded by an anesthesiologist blinded to the anesthesia technique. Simple verbal orders ("open your eyes", "squeeze my hand", "open your mouth") were repeated every $15 \mathrm{sec}$.

Postoperatively, subjects received crystalloids 5 $\mathrm{mL} \cdot \mathrm{kg}^{-1} \cdot \mathrm{hr}^{-1}$ and were allowed to drink water after three hours, if tolerated. All subjects stayed in the hospital for at least $24 \mathrm{hr}$.

The incidence of postoperative nausea (PON), vomiting (POV), or PONV and the use of rescue antiemetics were recorded at two and $24 \mathrm{hr}$ after surgery. The severity of PON and pain were evaluated using a $100-\mathrm{mm}$ visual analogue scale (VAS; $0=$ no pain/nausea, $100=$ maximum pain/nausea) at the same time points. The postoperative nausea VAS score was recorded for each episode, with the highest score used for statistical analysis. Subjects were considered to have PONV if they experienced at least one episode of nausea (VAS $>0$ ), vomiting, or retching, or any combination of these events. Postoperative vomiting was defined as at least one episode of vomiting or retching during the initial $24 \mathrm{hr}$ postoperatively. Postoperative nausea and vomiting, PON, and POV were defined as early (during the first two hours, in the postoperative recovery area) or late (during the first 2-24 postoperative hours, on the ward). The same anesthesiologist blinded to the anesthesia technique collected all postoperative data. A rescue antiemetic (metoclopramide $0.4 \mathrm{mg} \cdot \mathrm{kg}^{-1} i v$ ) was given to those who experienced two or more episodes of vomiting and/or retching within a period of $30 \mathrm{~min}$, any nausea lasting $>15 \mathrm{~min}$, nausea VAS score $\geq 50 \mathrm{~mm}$, or when requested for PONV management. The pain VAS score and total dose of postoperative opioids were also recorded at two and $24 \mathrm{hr}$ after surgery. Diclofenac $75 \mathrm{mg}$ im was given immediately after surgery and, if needed, 12 $\mathrm{hr}$ later. For severe pain (VAS $>40 \mathrm{~mm}$ ) meperidine 50 to $100 \mathrm{mg} \mathrm{iv}$ was used and repeated every four hours, as needed.

The sample size for recovery time (primary endpoint) was calculated on the assumption that 15 (SD 7) min would be needed for early recovery (following commands) for the $\mathrm{GO}_{2}$ patients and that the $\mathrm{GN}_{2} \mathrm{O}$ patients would require four minutes less time (11 [SD 5] min). We would need 38 patients in each group for the primary outcome to have a 
Table 2 Recovery data

\begin{tabular}{|c|c|c|c|c|}
\hline & $\begin{array}{l}\mathrm{GO}_{2} \text { (air) } \\
(n=42)\end{array}$ & $\begin{array}{l}\mathrm{GN}_{2} \mathrm{O}\left(\mathrm{air} / \mathrm{N}_{2} \mathrm{O}\right) \\
(n=40)\end{array}$ & $\begin{array}{l}\text { Difference in means } \\
(95 \% \mathrm{CI})\end{array}$ & $P$ value \\
\hline Tracheal extubation (min) & $7.5(3.7)$ & $5.4(2.9)$ & $2.1(0.6$ to 3.4$)$ & 0.009 \\
\hline Open eyes (min) & $13.9(5.6)$ & $10.0(4.6)$ & $3.9(1.6$ to 6.1$)$ & 0.001 \\
\hline Follow commands (min) & $15.1(5.7)$ & $11.8(5.1)$ & $3.4(1.0$ to 5.7$)$ & 0.006 \\
\hline Orientation (min) & $17.7(6.4)$ & $13.9(6.6)$ & $3.8(0.9$ to 6.7$)$ & 0.010 \\
\hline Pain at $2 \mathrm{hr}$ (VAS, 0-100 mm) & $47.4(15.2)$ & $38.2(14.6)$ & $9.2(2.6$ to 15.8$)$ & 0.008 \\
\hline Pain at $24 \mathrm{hr}$ (VAS, $0-100 \mathrm{~mm})$ & $12.9(13.0)$ & $13.2(12.4)$ & $0.3(-5.9$ to 5.3$)$ & 0.860 \\
\hline Meperidine (mg) & $62.2(25.6)$ & $58.5(48.6)$ & $3.7(-13.3$ to 20.7$)$ & 0.665 \\
\hline Meperidine ( $n$ patients) & $42(100 \%)$ & $33(82.5 \%)$ & RR 0.83 (0.72 to 0.95$)$ & 0.005 \\
\hline
\end{tabular}

Data presented as means (SD) and $n(\%)$

$\mathrm{CI}=$ confidence interval; $\mathrm{GO}_{2}=$ oxygen group; $\mathrm{GN}_{2} \mathrm{O}=$ nitrous oxide group; $\mathrm{RR}=$ relative risk; VAS = visual analogue score

power of 0.8 and an alpha level of 0.05 . The study was also designed to have adequate power for the secondary endpoint, the incidence of PONV. The sample size for PONV was calculated based on the results from our previous study, which had a $30 \%$ incidence of PONV among the $\mathrm{GO}_{2}$ patients and $60 \%$ among the $\mathrm{GN}_{2} \mathrm{O}$ patients. ${ }^{4}$ At least 40 subjects per group would be needed to show the difference between groups with a power of 0.8 and an alpha level of 0.05. Although the incidences we used for the power calculation of PONV in this study were much higher than those reported in the literature - e.g., ENIGMA II (11\% vs $15 \%)$ and IMPACT (31\% vs 35\%) trials $^{6,7}$ - the incidence was based on a previously reported study conducted on the same surgical population under similar conditions. ${ }^{4}$ The Chi-square and Mann-Whitney tests were used to analyze the data. $P<0.05$ was considered to indicate statistical significance.

\section{Results}

Overall, 82 of the 100 subjects enrolled between September 2006 and November 2010 completed the study. The Figure presents a flow chart of the study enrolment and reasons for exclusion from the analysis. There were no differences between the two groups regarding the participants' age, body mass index, ASA physical status, smoking status, history of PONV and/or motion sickness, probability of PONV using the Apfel risk score, duration of anesthesia and surgery, use of the induction agent, or intraoperative use of fentanyl (Table 1). On average, the $\mathrm{GN}_{2} \mathrm{O}$ patients received $\mathrm{N}_{2} \mathrm{O}$ at the end of anesthesia for 27 (SD 10) min. The $\mathrm{GN}_{2} \mathrm{O}$ patients recovered significantly faster than the $\mathrm{GO}_{2}$ patients. They were, on average, extubated two minutes earlier, and they opened their eyes, followed commands, and became oriented about four minutes more rapidly (Table 2).
All subjects in both groups received diclofenac at the end of the surgery. Although there was no difference in the amount of meperidine and additional diclofenac administered to the two groups, the $\mathrm{GN}_{2} \mathrm{O}$ patients had less pain at two hours postoperatively (Table 2). Furthermore, one in six of the $\mathrm{GN}_{2} \mathrm{O}$ patients did not require postoperative opioids, whereas all of the $\mathrm{GO}_{2}$ patients were given at least one dose of meperidine (Table 2). At $24 \mathrm{hr}$, there was no difference in pain between the groups (Table 2). Faster early recovery was not accompanied by an increased risk of PONV. There were no differences between groups at any point regarding nausea and/or vomiting (Table 3). Moreover, the $\mathrm{GN}_{2} \mathrm{O}$ patients received significantly less metoclopramide (Table 3). No adverse events were noted during the study.

\section{Discussion}

This study suggested that adding $70 \% \mathrm{~N}_{2} \mathrm{O}$ during the last $30 \mathrm{~min}$ of general anesthesia maintained with isoflurane hastened extubation and early recovery without increasing the incidence of PONV in patients undergoing laparoscopic gynecologic surgery. This practice may reduce pain scores at two hours postoperatively and the overall need of postoperative opioids.

Thus, in our opinion, the clinical importance of the results of this study for anesthesia providers who routinely use isoflurane is that they could add $\mathrm{N}_{2} \mathrm{O}$ at the end of surgery without worrying about increasing the risk of PONV and achieve recovery times similar to those when sevoflurane or desflurane is used. For anesthesia providers who do not use isoflurane, our results indicate that they could consider using the isoflurane $/ \mathrm{N}_{2} \mathrm{O}$ at the end (ISONATE) technique without concerns of increased morbidity/PONV and with recovery times similar to those achieved using sevoflurane alone. 
Table 3 Postoperative nausea and vomiting data

\begin{tabular}{lcll}
\hline & $\begin{array}{l}\mathrm{GO}_{2}(\text { air }) \\
(n=42)\end{array}$ & $\begin{array}{l}\mathrm{GN}_{2} \mathrm{O}\left(\text { air/ } \mathrm{N}_{2} \mathrm{O}\right) \\
(n=40)\end{array}$ & $\begin{array}{l}\text { Relative risk } \\
\text { (95\% CI })\end{array}$ \\
\hline PONV 0-2 hr & $28(66.6 \%)$ & $20(50 \%)$ & $0.75(0.52$ to 1.09$)$ \\
PONV 2-24 hr & $15(35.7 \%)$ & $17(42.5 \%)$ & $1.19(0.69$ to 2.05$)$ \\
PONV 24 hr & $31(73.8 \%)$ & $27(67.5 \%)$ & $0.91(0.69$ to 1.2$)$ \\
PON 0-2 hr & $27(64.2 \%)$ & $19(47.5 \%)$ & $0.74(0.50$ to 1.10$)$ \\
PON 2-24 hr & $13(30.9 \%)$ & $17(42.5 \%)$ & $1.37(0.77$ to 2.45$)$ \\
PON 24 hr & $30(71.4 \%)$ & $27(67.5 \%)$ & $0.96(0.71$ to 1.26$)$ \\
Nausea (VAS, 0-100 mm) & $30.1(23.3)$ & $24.5(21.2)$ & MD 5.6 $(-4.2$ to 15.4$)$ \\
POV 0-2 hr & $21(50 \%)$ & $15(37.5 \%)$ & $0.75(0.45$ to 1.24$)$ \\
POV 2-24 hr & $14(33.3 \%)$ & $10(25 \%)$ & $0.75(0.38$ to 1.49$)$ \\
POV 24 hr & $26(61.9 \%)$ & $20(50 \%)$ & $0.81(0.55$ to 1.19$)$ \\
Vomiting episodes & $1.8(2.8)$ & $0.9(1.2)$ & MD $0.9(-0.1$ to 1.9$)$ \\
Metoclopramide $(\mathrm{mg})$ & $11.7(10.7)$ & $6.6(8.8)$ & MD 5.1 (0.8 to 9.4)
\end{tabular}

Data presented as $n(\%)$ and mean (SD)

$\mathrm{PON}=$ postoperative nausea $\mathrm{PONV}=$ postoperative nausea and vomiting; $\mathrm{POV}=$ postoperative vomiting

$\mathrm{CI}=$ confidence interval $\mathrm{GO}_{2}=$ oxygen group $\mathrm{GN}_{2} \mathrm{O}=$ nitrous oxide group $\mathrm{MD}=$ mean difference. $\mathrm{PON}=$ postoperative nausea; $\mathrm{POV}=$ postoperative vomiting; $\mathrm{PONV}=$ postoperative nausea and vomiting

Although isoflurane is no longer frequently used in North America, it remains the predominant VA used worldwide. A recent study of cardiac surgery showed that sevoflurane was not superior to isoflurane regarding any important clinical outcomes. ${ }^{8}$ The study also calculated cost savings if isoflurane was used for a $4.5-\mathrm{hr}$ operation (\$5.25 vs $\$ 41.24$, isoflurane vs sevoflurane, respectively), potentially saving US $\$ 10$ million in the Unites States alone if isoflurane was used instead of sevoflurane for all cardiac operations. $^{8}$ The savings would clearly be greater if isoflurane was used instead of sevoflurane for general surgery. These figures suggest that isoflurane might not yet be obsolete and that clinicians should consider using the ISONATE technique.

The faster early recovery in the $\mathrm{N}_{2} \mathrm{O}$ group in our study (orientation to time and place was $3.8 \mathrm{~min}$ faster) was comparable to the results of a meta-analysis comparing desflurane with isoflurane anesthesia (4.4 min). ${ }^{1}$ In another recent meta-analysis, the percentage reductions in time to extubation were $34 \%$ (95\% confidence interval [CI] 28 to 39) for desflurane and $13 \%$ (95\% CI 1 to 23) for sevoflurane, ${ }^{9}$ which are comparable to our results of $27 \%$ (95\% CI 18 to 38). These percentages suggest that adding $\mathrm{N}_{2} \mathrm{O}$ at the end of isoflurane anesthesia may result in a clinical response similar to the early recovery seen when using sevoflurane or desflurane.

Nitrous oxide has been used for years with a relatively good safety record, although its safety was recently challenged by two large multicenter trials. ${ }^{5,9}$ In the ENIGMA trial, with 2,050 patients, the $\mathrm{N}_{2} \mathrm{O}$-free patients had a significantly lower combined rate of major complications and lower incidence of severe PONV. ${ }^{5}$ In the ENIGMA-II trial, with $>7,000$ patients, $\mathrm{N}_{2} \mathrm{O}$ avoidance did not reduce the incidence of major perioperative cardiac events and death. ${ }^{7,10}$

Nitrous oxide emetic properties had been controversial until the large, multifactorial IMPACT trial confirmed that use of $\mathrm{N}_{2} \mathrm{O}$ increased the risk of PONV. ${ }^{6}$ This difference in results could be partly explained not only by the different inspiratory concentrations of $\mathrm{N}_{2} \mathrm{O}$ used in studies but also the different durations of $\mathrm{N}_{2} \mathrm{O}$ administration. Hence, the total amount of $\mathrm{N}_{2} \mathrm{O}$ delivered (concentration + duration) to the patient may be important.

Recently, it was suggested that the risk of PONV is increased with an increased inspiratory concentration of $\mathrm{N}_{2} \mathrm{O} .{ }^{4}$ When the $\mathrm{N}_{2} \mathrm{O}$ inspiratory concentration was increased from $50 \%$ to $70 \%$, PONV increased from $46 \%$ to $62 \%$. There is a paucity of data on the duration of $\mathrm{N}_{2} \mathrm{O}$ exposure and PONV. A recent meta-analysis combined the data of 29 studies ( $>10,000$ patients) and found that the risk of PONV increased by $20 \%$ per hour of $\mathrm{N}_{2} \mathrm{O}$ exposure after the first $45 \mathrm{~min}^{11}$ The statistical analysis, however, was later questioned. ${ }^{12}$ Moreover, the inspiratory $\mathrm{N}_{2} \mathrm{O}$ concentrations were not taken into account for either the analysis or the stratification by the type of surgery (the majority of shorter-duration surgeries were gynecological). ${ }^{13}$ Only one published study specifically explored the duration of anesthesia with $\mathrm{N}_{2} \mathrm{O}$ and PONV. ${ }^{14}$ The study was small (30 patients in the $\mathrm{N}_{2} \mathrm{O}$ group, 154 in the $\mathrm{O}_{2}$ group), and randomization could have been biased (only one anesthesia provider was using $\mathrm{N}_{2} \mathrm{O}$; the other two providers did not). ${ }^{14}$ In addition, the $\mathrm{N}_{2} \mathrm{O}$ inspiratory 
concentration was not standardized. The results of the study suggested that exposure to $\mathrm{N}_{2} \mathrm{O}$ for three hours or more could increase the risk for PONV compared with a shorter exposure. ${ }^{14}$ In our study, we chose to add $\mathrm{N}_{2} \mathrm{O}$ for 30 min because a shorter duration of $\mathrm{N}_{2} \mathrm{O}$ administration might not have a detrimental effect on PONV. Indeed, we used $\mathrm{N}_{2} \mathrm{O}$ for only $27 \pm 10 \mathrm{~min}$ on average and found no difference in PONV between the two groups. It appears that the short exposure of $70 \% \mathrm{~N}_{2} \mathrm{O}$ is not long enough to trigger the emetic mechanism.

The mechanism of $\mathrm{N}_{2} \mathrm{O}$-associated PONV has not been well studied, but it could include an increase in the middle ear pressure, bowel distension, activation of the dopaminergic system in the chemoreceptor trigger zone, and interaction with opioid receptors. In our study, not only was there no difference in PONV between groups, the participants in the oxygen group required more rescue antiemetic. Also, more subjects were treated for PONV $(62 \%, 26 / 42)$ than those who received $\mathrm{N}_{2} \mathrm{O}(40 \%, 16 / 40)$. One of the explanations for this surprising result could be that significantly fewer subjects in the $\mathrm{N}_{2} \mathrm{O}$ group required postoperative opioids (17.5\% vs $0 \%: \mathrm{GO}_{2}$ vs $\mathrm{GN}_{2} \mathrm{O}, P=$ 0.005 ). Additionally, those who received $\mathrm{N}_{2} \mathrm{O}$ at the end of anesthesia required less postoperative opioids and had significantly less pain at two hours postoperatively. Our data support the ENIGMA trial results, which suggested that $\mathrm{N}_{2} \mathrm{O}$ might have a postoperative analgesic effect. ${ }^{15}$ The retrospective review of ENIGMA subjects showed a shorter use of patient-controlled analgesia in the $\mathrm{N}_{2} \mathrm{O}$ group but no difference in pain scores or opioid usage.

The mechanism of $\mathrm{N}_{2} \mathrm{O}$ analgesic action is not clearly understood. $\mathrm{N}_{2} \mathrm{O}$ acts on various receptors at different sites of the central nervous system (dopaminergic, glutamatergic, adrenergic, benzodiazepine), but its activity as an $N$-methyl-D-aspartate antagonist may be important in preventing central sensitization. ${ }^{16}$ Shorter exposure to $\mathrm{N}_{2} \mathrm{O}$ could have more effect on postoperative pain than a longer exposure because more $\mathrm{N}_{2} \mathrm{O}$ exposure could induce acute tolerance and diminish its postoperative analgesic and opioid sparing effect. Indeed, a study in healthy volunteers exposed to $60-80 \%$ of $\mathrm{N}_{2} \mathrm{O}$ for three hours found that the maximum analgesic effect was observed after 20-30 min of exposure to $\mathrm{N}_{2} \mathrm{O}$. It then gradually decreased and was completely absent in all volunteers within 150 min. ${ }^{17}$

There are several limitations in our study. First, this study was conducted in a single centre with only one type of surgical procedure, the duration of which was about two hours. Therefore, the results may not be generalized to other types of surgery or for a longer duration of isoflurane anesthesia because the isoflurane context decrement time increases more steeply after $100 \mathrm{~min}$ of delivery. This could significantly prolong recovery compared with a shorter exposure. Adding $\mathrm{N}_{2} \mathrm{O}$ at the end of several hours of isoflurane anesthesia could potentially hasten recovery even more because of the second gas effect on emergence from anesthesia. ${ }^{18} \mathrm{~A}$ larger, multicenter study with a longer duration of anesthesia would be needed to confirm this point. Using the PONV incidences in the ENIGMA II and IMPACT trials, 2,815 and 1,271 subjects per group, respectively, would be needed to show that adding $\mathrm{N}_{2} \mathrm{O}$ at the end of anesthesia would increase the PONV incidence with a power of 0.8 and $P<0.05{ }^{6,7}$

Second, PONV prophylaxis was not given to subjects in either group as it was the standard of care in our hospital at the time of the study. Although administering the same antiemetic prophylaxis in both groups would likely decrease the incidence of PONV in both groups, it would not have an influence on extubation or orientation times. When PONV prophylaxis was used in the ENIGMA II trial, there was no significant trend to increase the incidence of severe PONV using $\mathrm{N}_{2} \mathrm{O}(13.1 \%$ vs $11.8 \%) .^{7}$ Assuming the same incidence, a study of 11,539 subjects per group would be needed to show the difference with a power of 0.8 .

Third, the difference in extubation time between our study groups was modest (two minutes). It was done at a "deeper" extubation stage, however, when subjects met ventilation criteria for the extubation (the standard procedure in our hospital at the time of the study). We did not want to change the hospital protocol for this study. If extubation had been performed after the subjects were following commands, it could be expected that the difference would be at least as much as the difference in the time for following commands (3.5 min), if not longer.

In summary, adding $70 \% \mathrm{~N}_{2} \mathrm{O}$ during the last $30 \mathrm{~min}$ of isoflurane-maintained anesthesia hastens early recovery without increasing the incidence of PONV. It may also be associated with lower pain scores and less opioid use during the early recovery period.

Acknowledgements The authors appreciate greatly the help of Dr. Simon Mikulandra from Ordensklinikum Linz - Elisabethinen, Linz, Austria with the statistical analysis.

Conflicts of interest Tong J. Gan: current and previous research grant support and honoraria from Fresenius Kabi, Mallinckrodt, Merck, Pacira, and Edwards. None of the above companies manufacture or market nitrous oxide.

Editorial responsibility This submission was handled by Dr. Philip M. Jones, Associate Editor, Canadian Journal of Anesthesia.

Author contributions Boris Mraovic helped with the conception and design of the study, data analysis, interpretation of the data. He also drafted and prepared the manuscript and approved the final manuscript. Boris Mraovic attests to the integrity of the original data and the analysis reported in this manuscript. Tatjana Simurina helped with conception and design of the study; conducted the study; 
collected and analysed data; prepared the manuscript; and approved the final manuscript. Tatjana Simurina attests to the integrity of the original data and the analysis reported in the manuscript. Tatjana Simurina is the archival author. Tong J. Gan helped prepare the manuscript and approved the final manuscript.

Funding None.

\section{References}

1. Dexter F, Tinker JH. Comparisons between desflurane and isoflurane or propofol on time to following commands and time to discharge. A metaanalysis. Anesthesiology 1995; 83: 77-82.

2. Neumann MA, Weiskopf RB, Gong DH, Eger EI 2nd, Ionescu P. Changing from isoflurane to desflurane toward the end of anesthesia does not accelerate recovery in humans. Anesthesiology 1998; 88: 914-21.

3. Peyton PJ, Chao I, Weinberg L, Robinson GJ, Thompson BR. Nitrous oxide diffusion and the second gas effect on emergence from anesthesia. Anesthesiology 2011; 114: 596-602.

4. Mraovic B, Simurina T, Sonicki Z, Skitarelic N, Gan TJ. The dose-response of nitrous oxide in postoperative nausea in patients undergoing gynecologic laparoscopic surgery: a preliminary study. Anesth Analg 2008; 107: 818-23.

5. Myles PS, Leslie K, Chan MT, et al; ENIGMA Trial Group. Avoidance of nitrous oxide for patients undergoing major surgery: a randomized controlled trial. Anesthesiology 2007; 107: 221-31.

6. Apfel CC, Korttila K, Abdalla M, et al; IMPACT Investigators. A factorial trial of six interventions for the prevention of postoperative nausea and vomiting. N Engl J Med 2004; 350: 2441-51.

7. Myles PS, Chan MT, Kasza J, et al. Severe nausea and vomiting in the evaluation of Nitrous Oxide in the Gas Mixture for Anesthesia II Trial. Anesthesiology 2016; 124: 1032-40.
8. Jones PM, Bainbridge D, Chu MW, et al. Comparison of isoflurane and sevoflurane in cardiac surgery: a randomized noninferiority comparative effectiveness trial. Can J Anesth 2016; 63: 1128-39.

9. Agoliati A, Dexter F, Lok J, et al. Meta-analysis of average and variability of time to extubation comparing isoflurane with desflurane or isoflurane with sevoflurane. Anesth Analg 2010; 110: 1433-9.

10. Myles PS, Leslie K, Peyton P, et al; ANZCA Trials Group. Nitrous oxide and perioperative cardiac morbidity (ENIGMA-II) trial: rationale and design. Am Heart J 2009; 157: 488-94.

11. Peyton $P J, W u C Y$. Nitrous oxide-related postoperative nausea and vomiting depends on duration of exposure. Anesthesiology 2014; 120: 1137-45.

12. Pace NL. Questioning a relationship between nitrous oxide duration of exposure and postoperative nausea and vomiting. Anesthesiology 2014; 121: 1356-8.

13. Zhou L, Chen $C, Y u H$. Nitrous oxide-related postoperative nausea and vomiting depends on duration of exposure: more questions than answers. Anesthesiology 2014; 121: 1356.

14. Smiley BA, Paradise NF. Does the duration of $\mathrm{N}_{2} \mathrm{O}$ administration affect postoperative nausea and vomiting? Nurse Anesth 1991; 2: 13-8.

15. Stiglitz DK, Amaratunge LN, Konstantatos AH, Lindholm DE. Intraoperative nitrous oxide as a preventive analgesic. Anaesth Intensive Care 2010; 38: 890-3.

16. Richebe $P$, Rivat $C$, Creton $C$, et al. Nitrous oxide revisited: evidence for potent antihyperalgesic properties. Anesthesiology 2005; 103: 845-54.

17. Rupreht J, Dworacek B, Bonke B, Dzoljic MR, van Eijndhoven $J H$, de Vlieger $M$. Tolerance to nitrous oxide in volunteers. Acta Anaesthesiol Scand 1985; 29: 635-8.

18. Eger EI 2nd, Shafer SL. Tutorial: context-sensitive decrement times for inhaled anesthetics. Anesth Analg 2005; 101: 688-96. 